\title{
Langue, langage et discours : l'homme dans la didactique
}

\section{Michèle Verdelhan-Bourgade}

\section{(2) OpenEdition \\ Journals}

Édition électronique

URL : http://journals.openedition.org/trema/1657

DOI : $10.4000 /$ trema. 1657

ISSN : 2107-0997

Éditeur

Faculté d'Éducation de l'université de Montpellier

Édition imprimée

Date de publication : 1 juillet 2000

Pagination : 1-2

ISSN : 1167-315X

\section{Référence électronique}

Michèle Verdelhan-Bourgade, "Langue, langage et discours : l'homme dans la didactique », Tréma [En ligne], 17 | 2000, mis en ligne le 27 octobre 2010, consulté le 22 septembre 2020. URL : http:// journals.openedition.org/trema/1657 ; DOI : https://doi.org/10.4000/trema.1657

Ce document a été généré automatiquement le 22 septembre 2020

Trema 


\title{
Langue, langage et discours : l'homme dans la didactique
}

\author{
Michèle Verdelhan-Bourgade
}

1 Les travaux récents en didactique du langage semblent redécouvrir «l'homme dans la langue ", selon la formule d'Émile BENVENISTE : en français langue maternelle, après des années consacrées à la production écrite à partir de l'étude technique des types de texte, le retour en force de l'oral, de la maternelle au lycée, dénote une attention nouvelle portée au sujet parlant. En français langue étrangère ou langue seconde, la rigueur méthodologique laisse place à des tentatives diversifiées, souples, intégrant les divers acquis du passé aussi bien que les nouveautés technologiques, dans le souci de se rapprocher de l'apprenant et du contexte local. Tout ce mouvement autour de l'humain se développe parallèlement à un appel insistant à l'utilisation des technologies informatiques, et comme en contre point, le discours sur l'individu et son apprentissage compensant la froideur de la machine.

2 Pour jalonner cette redécouverte de l'individu, cette livraison de TRÉMA propose des sortes de variations sur la dimension anthropologique de la didactique de la langue et $\mathrm{du}$ langage. Si tous les auteurs du numéro se référent à une «didactique anthropologique», l'humain s'y insère en effet à des degrés divers, depuis un rôle central jusqu'à sembler disparaitre derrière la technicité des analyses de la langue ou $\mathrm{du}$ discours. On peut vouloir former un homme communiquant (A. COÏANIZ), avec son épaisseur psychologique et son ancrage social, un citoyen militant, comme le voulait la Révolution française (J.-G. LAPACHERIE), une personne active intellectuellement et socialement (M. CELLIER et P. DEMOUGIN), un homme capable de tirer toutes les ressources du discours dans l'argumentation grâce à la rhétorique (B. SCHOULER), ou un utilisateur linguistiquement correct de la langue (K: H. EGGENSPERGER). 
Quelques cloisonnements traditionnels en didactique n'ont pas été repris dans cet ensemble. Français langue maternelle et français langue étrangère, par exemple : non qu'on considère que les différences didactiques n'ont pas lieu d'être, mais plutôt parce que les deux didactiques s'enrichissent l'une de l'autre et se rencontrent sur des préoccupations parfois communes. Ou encore études historiques, contemporaines ou perspectives : une didactique de l'humain se bâtit patiemment au cours des siècles, et les tentatives passées servent de repères aux constructions en cours. C'est une des richesses de TREMA que de pouvoir s'appuyer sur des équipes de recherche et un Centre de documentation en histoire de l'éducation alliant histoire et modernité.

\section{AUTEUR}

MICHĖLE VERDELHAN-BOURGADE

IUFM de Montpellier 